\title{
Dental caries and oral health-related factors in a sample of Greek preschool children: reply to comment by Larmas
}

\author{
V. Boka
}

Received: 26 February 2014 / Accepted: 27 February 2014/Published online: 20 March 2014

(C) European Academy of Paediatric Dentistry 2014

\section{Dear Editor,}

We share Dr. Larmas's uneasiness on the correctness of the epidemiological terms used in general, particularly in older population samples than ours (Larmas 2014; Boka et al. 2013). Dr. Larmas is absolutely entitled to state that the ' $\mathrm{f}$ ' or ' $\mathrm{m}$ ' components do not represent the current levels of caries. In this particular sample of almost entirely 3-5.5year-olds, however, both were negligible components of the dmfs index, and recorded caries was largely represented by the 'd' component. Whether this is closely related to recent or even present caries activity, although highly likely to be so, was not investigated.

We maintain that reading the debated sentence as: "The manifest caries prevalence was $22.6 \%$ " answers the writer's rightful objection.

Regarding Dr. Larmas's disappointment regarding the existing scientific knowledge on dental caries prevalence, we think this is also a matter of definition. Questions such as how many teeth or people this widespread chronic disease has affected or how active it presently is, and more, all bear their own meaning are addressed by epidemiologists.

\section{References}

Larmas M. Comment on Boka et al. Dental caries and oral healthrelated factors in a sample of Greek preschool children. Eur Arch Paediatr Dent. 2014; doi:10.1007/s40368-014-0120-5.

Boka V, Trikaliotis A, Kotsanos N, Karagiannis V. Dental caries and oral health-related factors in a sample of Greek preschool children. Eur Arch Paediatr Dent. 2013;14:363-8. doi:10.1007/ s40368-013-0097-5.
V. Boka $(\bowtie)$

Papafi 88, 54453 Thessaloniki, Greece

e-mail: vanessaboka@yahoo.gr 